\title{
Prediction and identification of B-cell epitopes for tumor necrosis factor- $\alpha$
}

\author{
JUN ZHANG $^{1}$, YING CUI ${ }^{2}$, YINFANG WU ${ }^{3}$, HUIJU WANG $^{4}$ and JINJING KE $^{1}$ \\ Departments of ${ }^{1}$ Gastroenterology and ${ }^{2}$ Nuclear Medicine, Zhejiang Provincial People's Hospital, Hangzhou, Zhejiang 310014; \\ ${ }^{3}$ The Second Clinical Medical College, Zhejiang Chinese Medical University, Hangzhou, Zhejiang 310053; \\ ${ }^{4}$ Key Laboratory of Gastroenterology of Zhejiang, Zhejiang Provincial People's Hospital, \\ Hangzhou, Zhejiang 310014, P.R. China
}

Received August 16, 2016; Accepted May 11, 2017

DOI: $10.3892 / \mathrm{mmr} .2017 .7007$

\begin{abstract}
The aim of the present study was to predict and identify B-cell epitopes for mouse tumor necrosis factor- $\alpha$ $(\mathrm{mTNF}-\alpha)$. DNAStar and BcePred software were used to predict B-cell epitopes for mTNF- $\alpha$. A predicted eight-branch multiple antigenic polypeptide (MAP) was synthesized and used to immunize BALB/c mice, combined with a promiscuous helper interleukin-1 $\beta$ epitope (VQGEESNDK, amino acids 163-171). The serum titer was measured. The specificity and avidity were determined by western blotting and indirect enzyme-linked immunosorbent assay (ELISA). Amino acids 54-65 (MAP1) and 78-92 (MAP2) of mTNF- $\alpha$ were predicted as most likely to be B-cell epitopes. Dynamic monitoring of antibody concentration demonstrated that MAP1 and MAP2 may induce the production of specific antibodies with a higher antibody level for MAP2. Furthermore, MAP1 and MAP2 were confirmed to induce mTNF- $\alpha$-specific antibodies by western blotting. Indirect ELISA was used to confirm that MAP2 had the highest affinity with commercial anti-mTNF- $\alpha$ antibody. Amino acids 54-65 and 78-94 of mTNF- $\alpha$ are B-cell epitopes, wherein amino acids 78-94 have the strongest immunogenicity. The present study provides a theoretical basis for further research into the mTNF- $\alpha$ polypeptide antibody and a B-cell MAP vaccine.
\end{abstract}

\section{Introduction}

Tumor necrosis factor-alpha $(\mathrm{TNF}-\alpha)$ is a cytokine with complicated bioactivity. It is also a therapeutic target of autoantigens (1,2). In addition to killing tumor cells in vitro and in vivo, TNF- $\alpha$ may also induce inflammation, defend viral infection, regulate immunity, and promote cell proliferation

Correspondence to: Dr Jun Zhang, Department of Gastroenterology, Zhejiang Provincial People's Hospital, 158 Shangtang Road, Hangzhou, Zhejiang 310014, P.R. China E-mail: 19587372@qq.com

Key words: B lymphocyte, epitope, immunogenicity, multiple antigen peptide, tumor necrosis factor- $\alpha$, ulcerative colitis and activation (3-5). When TNF- $\alpha$ is overexpressed, it leads to various diseases, such as inflammatory bowel disease (3-5). These damages may be mitigated after neutralizing excess TNF- $\alpha$ using exogenous antibodies or soluble receptors. A monoclonal antibody against TNF- $\alpha$, infliximab, is the most commonly used exogenous antibody that has been approved for the treatment of Crohn's disease. Clinical trials demonstrated that infliximab also has a positive role in the treatment of ulcerative colitis (UC) $(6,7)$. However, using synthetic infliximab is a passive immunotherapy associated with many inherent defects, such as short duration and easy-to-induce hypersensitivity. Therefore, it would be a major breakthrough for the treatment of UC if the vaccine induced natural anti-TNF- $\alpha$ antibodies in vivo via active immunization.

The biological characteristics of TNF- $\alpha$ have no significant species specificity. The amino acids of murine TNF- $\alpha$ $(\mathrm{mTNF}-\alpha)$ are highly homologous to those of human TNF- $\alpha$ with a similar tertiary structure (8). Its precursor has 235 amino acid residues containing a signal peptide with 79 amino acid residues. Based on the primary structure of TNF- $\alpha$, bioinformatics was used to predict mTNF- $\alpha$ B-cell epitopes. Multiple antigenic polypeptides (MAPs) were synthesized using an eight-branch design (9). Interleukin-1 $\beta$ (IL-1 $\beta$ ) peptide 163-171, as a promiscuous helper epitope peptide (T-helper epitope), enhances immunity and humoral immune response of other antigen peptides (10). With combined immunization of animals, it induced the production of polyclonal antibodies $(9,10)$. A potential B-cell epitope peptide was obtained by indirect enzyme-linked immunosorbent assay (ELISA), western blotting and immunohistochemistry identification of the polyclonal antibody titer. The aim of the present study was to provide an initial experimental basis for active immunotherapy research for mTNF- $\alpha$ targeting UC in mice.

\section{Materials and methods}

Materials. The mTNF- $\alpha$ sequence was obtained from GenBank (https://www.ncbi.nlm.nih.gov/genbank/) as follows: MSTESMIRDVELAEEALPQKMGGFQNSRRCLCL SLFSFLLVAGATTLFCLLNFGVIGPQRDEKFPNGLPLISS MAQTLTLRSSSQNSSDKPVAHVVANHQVEEQLEWLSQ RANALLANGMDLKDNQLVVPADGLYLVYSQVLFKGQ 
GCPDYVLLTHTVSRFAISYQEKVNLLSAVKSPCPKDTPE GAELKPWYEPIYLGGVFQLEKGDQLSAEVNLPKYLDFAE SGQVYFGVIAL.

The following reagents and antibodies were purchased: Commercial recombinant mTNF- $\alpha$ protein (eBioscience; Thermo Fisher Scientific, Inc., Waltham, MA, USA), commercial polyclonal rabbit anti-mouse full-length TNF- $\alpha$ protein antibody (cat. no. 17590-1-AP). ProteinTech Group, Inc., Chicago,IL,USA),Freund's complete adjuvant (Sigma-Aldrich; Merck, KGaA, Darmstadt, Germany), incomplete adjuvant (Sigma-Aldrich; Merck KGaA), enzyme-labeled goat anti-mouse IgG-horseradish peroxidase II (cat. no. EK1003). Wuhan Boster Biological Technology, Ltd., Wuhan, China), wstern blotting chemiluminescence kit (Shanghai Kangcheng Sheng Biological Engineering Company, Shanghai, China) and protein marker (Bio-Rad Laboratories, Inc., Hercules, CA, USA). Mouse H22 hepatoma cells were obtained from Huazhong University of Science and Technology (Wuhan, China). A total of 80 female BALB/c mice (age, 4-5 weeks; weight, 18-25 g) were purchased from Shanghai Laboratory Animal Center (Shanghai, China; certificate no. SCXK20080115). The mice were placed in a plexiglass feeding box and kept on the clean shelf laminar flow. Each feeder box contained 3-4 mice under the following conditions: Constant temperature, $25-27^{\circ} \mathrm{C}$; humidity, $45-50 \%$; fresh air; high-level dust sterilization; and specific pathogen-free environment under a 12-h light/dark cycle. The animals had free access to sterilized water and food. The animal studies were approved by the ethics committee of Zhejiang Medical University (approval no. X1002623; Hangzhou, China). Live animal surgery was performed using $0.3 \%$ sodium pentobarbital $(30 \mathrm{mg} / \mathrm{kg})$. Upon completion of the experiment, the experimental animals were sacrificed by cervical dislocation.

B-cell epitope prediction. DNASTAR software version 7.1 (DNASTAR, Inc., Madison, WI, USA) and BcePred software (http://www.imtech.res.in/raghava/bcepred/) were used to analyze 235 amino acid sequences of mTNF- $\alpha$ to evaluate the physical and chemical properties of the encoded protein, such as hydrophilicity, accessibility, and plasticity, which was used for assessing the mTNF- $\alpha$ molecule antigenicity in the highly hydrophilic region. The two analyses were combined, and the overlapping result area was selected as the candidate mTNF- $\alpha$ B-cell epitope.

MAP synthesis. The MAP of the B-cell epitope peptide was synthesized by the Chinese Peptide Company Ltd. (Hangzhou, China). Based on the selected amino acid peptide and lysine core matrix, an eight-branch polypeptide was designed. Synthesis was performed on a peptide synthesizer using the solid-phase method, where amino acid peptides were linked with the 8 amino terminals of the 4 lysine located at the end of the MAP core structure. According to the amino acid sequence of the peptide, they were sequentially connected one by one from the carboxyl terminal to the amino terminal. Synthesized polypeptides purified by high-pressure liquid chromatography had a purity of $>97 \%$.

Binding force between MAP peptide and whole-protein $m T N F-\alpha$ antibodies. A 96-well ELISA plate was coated with
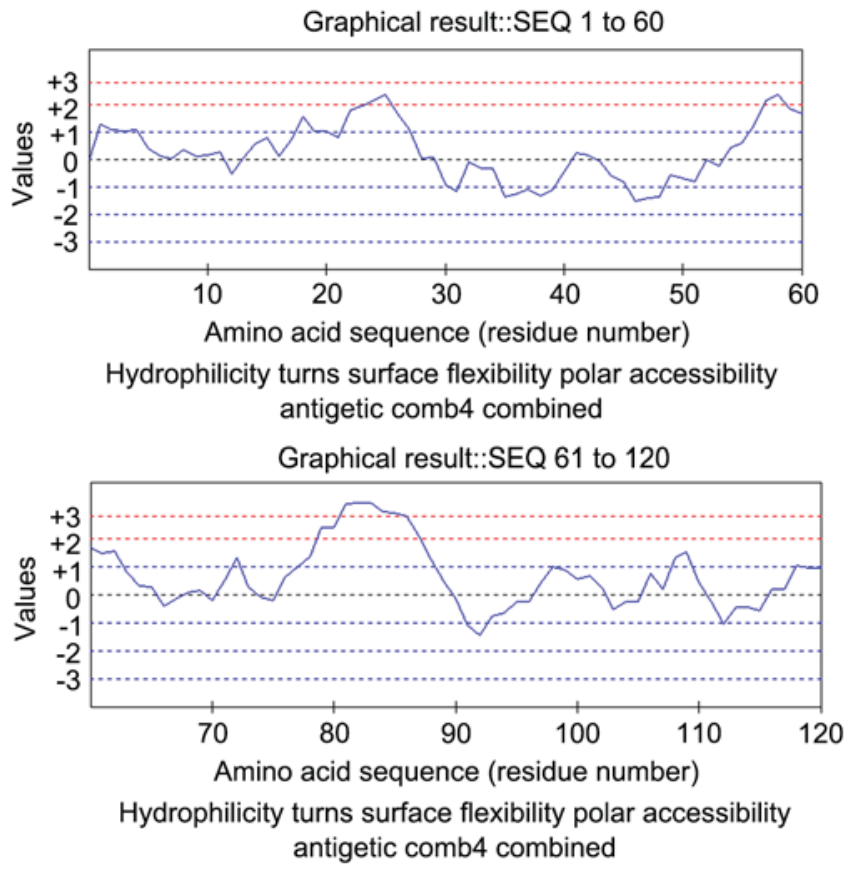

Figure 1. B cell epitopes of mouse tumor necrosis factor- $\alpha$ were predicted using Bcepred software. Amino acids 54-65 (GVIGPQRDEKFP) and 78-92 (LTLRSSSQNSSDKPV) exhibited good hydrophilicity, accessibility and plasticity.

$100 \mu 1$ of different MAPs or recombinant TNF- $\alpha$ protein at a concentration of $10 \mathrm{mg} / \mathrm{l}$ and maintained overnight at $4^{\circ} \mathrm{C}$. After blocking in $1 \%$ bovine serum albumin (BSA), a rabbit anti-mouse full-length TNF- $\alpha$ antibody $(1: 4,000 ; 100 \mu \mathrm{l} /$ well; cat. no. 17590-1-AP; ProteinTech Group, Inc.) was added, with normal BALB/c mouse serum (1:4,000) serving as a control. The results were expressed as the mean of three experiments. The absorbance of the plates were measured at a wavelength of $490 \mathrm{~nm}$ using an Imark Micoplate Absorbance Reader 13550 (Bio-RAD, Hercules, California, USA).

Material grouping. Eighty male BALB/c mice (age, 3-4 weeks; weight, 18-25 g), were randomly divided into four groups as follows: MAP1 group (amino acids 54-65), MAP2 group (amino acids 78-92), mTNF- $\alpha$ group, and phosphate-buffered saline (PBS) control group, with 20 mice in each group.

Immunization. The MAP1 and MAP2 groups were treated with eight-branch MAP immunogen. The mice were injected four times at 2-week intervals. The mice were first immunized with Freund's complete adjuvant (Sigma-Aldrich; Merck $\mathrm{KGaA}$ ) and boosted with incomplete Freund's adjuvant. The quantity of MAP used for the first immunization and boosting was $0.2 \mathrm{mg}$ per mouse. The mTNF- $\alpha$ control group was immunized with commercial recombinant mTNF- $\alpha$ protein at a dose of $20 \mu \mathrm{g}$ per mice. An equal quantity of T helper (TH) linear peptide was mixed, dissolved in $0.5 \mathrm{ml} \mathrm{PBS}$, and emulsified with $0.5 \mathrm{ml}$ Freund's adjuvant. Multi-point injections were performed intradermally on the backs of the mice. The PBS control group was also injected in the same way with $0.5 \mathrm{ml}$ PBS emulsified with an equal volume of Freund's complete adjuvant. 


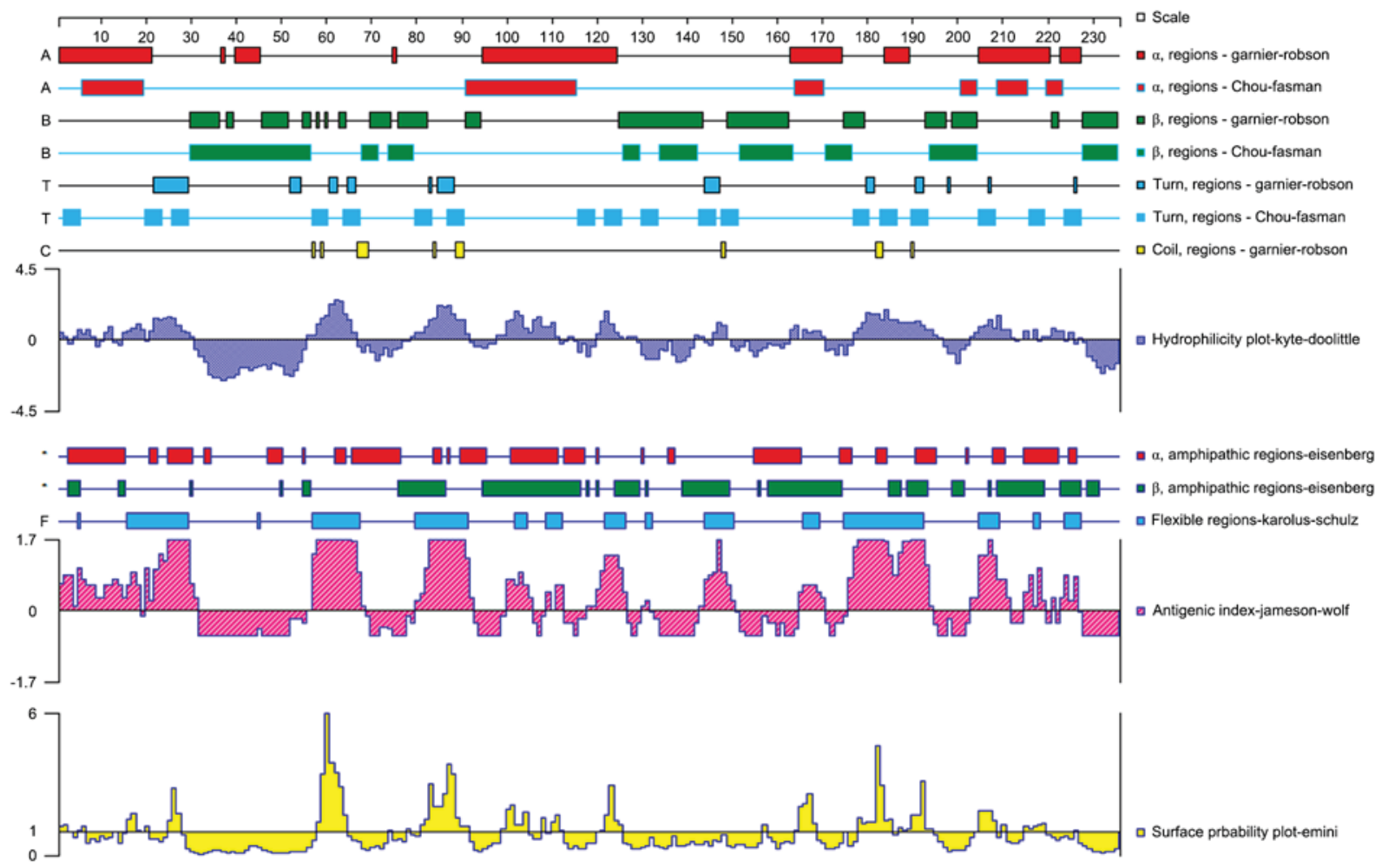

Figure 2. B cell epitopes of mouse tumor necrosis factor- $\alpha$ were predicted using DNAstar software. Amino acids 54-65 (GVIGPQRDEKFP) and 78-92 (LTLRSSSQNSSDKPV) exhibited good hydrophilicity and accessibility, and were located in protein extended structures or with no coil in the secondary structure.

Specimen collection and antibody detection. Retro-orbital blood $(0.5 \mathrm{ml}$ per mouse) was collected prior to the first immunization and 2 weeks after each immunization. Blood was collected a total of five times, and the mice were sacrificed by cervical dislocation. Serum was centrifuged for $4 \mathrm{~min}$ at $1,000 \mathrm{x} \mathrm{g}$ at $4^{\circ} \mathrm{C}$ and serum antibody titers were measured by standard indirect ELISA. The 96-well ELISA plate was coated with $10 \mathrm{mg} / 1 \mathrm{MAP} 1, \mathrm{MAP} 2, \mathrm{mTNF}-\alpha$ protein, or TH full peptide, $100 \mu \mathrm{l} /$ well, and maintained overnight at $4^{\circ} \mathrm{C}$. After blocking with $1 \% \mathrm{BSA}$, diluted test animal antiserum (dilutions ranging from 1:10,000 to 1:150,000) was used as the primary antibody for measurement, with pre-immune serum serving as a negative control. The results were presented as an A value (the mean of duplicated wells) and the experiments were repeated three times. The positive standard was $>2.1$, which was determined by the A value of the measured sample/negative control.

Protein electrophoresis and western blotting. H22 cells $\left(1 \times 10^{9}\right)$, which express mTNF- $\alpha$ stably and efficiently, were centrifugally washed. Pro-cooling suspended buffer solution $(1 \mathrm{ml})$ was added to the cell pellet for dissociation. The cells were vortexed for $5 \mathrm{~min}$ and centrifuged for $5 \mathrm{~min}$ at $10,000 \times \mathrm{g}$ at $4^{\circ} \mathrm{C}$. The supernatant was discarded, and total protein was extracted with an equal volume of $2 \mathrm{X}$ sodium dodecyl sulfate. A total of $20 \mathrm{mg}$ protein was analyzed by SDS polyacrylamide gel electrophoresis, then it was transferred to a polyvinylidene difluoride membrane at $400 \mathrm{~mA}$ for $90 \mathrm{~min}$, and a commercial mTNF- $\alpha$ protein served as a control and a mouse pre-immune serum served as a negative control.
Glyceraldehyde-3-phosphate dehydrogenase was selected as an internal reference. Chemiluminescent western blot detection was performed according to the manufacturer's instructions. The antibodies used for western blotting were either commercially available antibodies against full-length mTNF- $\alpha$ (cat. no. 17590-1-AP; ProteinTech Group, Inc.) (1:2,000) or mouse antiserum against MAP or mTNF- $\alpha$ (1:3,000 dilution). The specificity of the protein detected by the antiserum was determined by the molecular weight of the bands. BandScan version 5.0 software (Glyko Inc., Novato, CA, USA) was used to compare the relative gray scale of the bands.

Statistical analysis. SPSS 17.0 software (SPSS, Inc., Chicago, IL, USA) was used for statistical analysis. Quantitative data were presented as means \pm standard deviation. Pluralities of samples were compared using single factor analysis. The Student-Newman-Keuls post-test method was used for comparing variances between groups and $\mathrm{P}<0.05$ was considered to indicate a statistically significant difference.

\section{Results}

Prediction of B-cell epitope and peptide synthesis. The predictions of B-cell epitopes using BcePred and DNAStar are presented in Figs. 1 and 2, respectively. The results of the two methods were almost identical. Amino acids 54-65 (GVIGPQRDEKFP) and 78-92 (LTLRSSSQNSSDKPV) exhibited good hydrophilicity, accessibility and plasticity, and were located in protein extended structures or with no coil in the secondary structure. They were presumed to be B-cell epitopes. 
Table I. B cell epitopes of mTNF- $\alpha$ were predicted using BcePred (http://www.imtech.res.in/raghava/bcepred/) and DNAStar software (DNASTAR, Inc., Madison, WI, USA).

\begin{tabular}{lcll}
\hline MAP & Amino acid & Peptide & Software \\
\hline MAP1 & $54-65$ & GVIGPQ & BcePred, \\
& & RDEKFP & DNAStar \\
MAP2 & $78-92$ & LTLRSSSQ & BcePred, \\
& & NSSDKPV & DNAStar \\
\hline
\end{tabular}

mTNF- $\alpha$, mouse tumor necrosis factor- $\alpha$; MAP, multiple antigenic polypeptide; MAP1, amino acids 54-65 of mTNF- $\alpha$; MAP2, amino acids 78-92 of mTNF- $\alpha$.

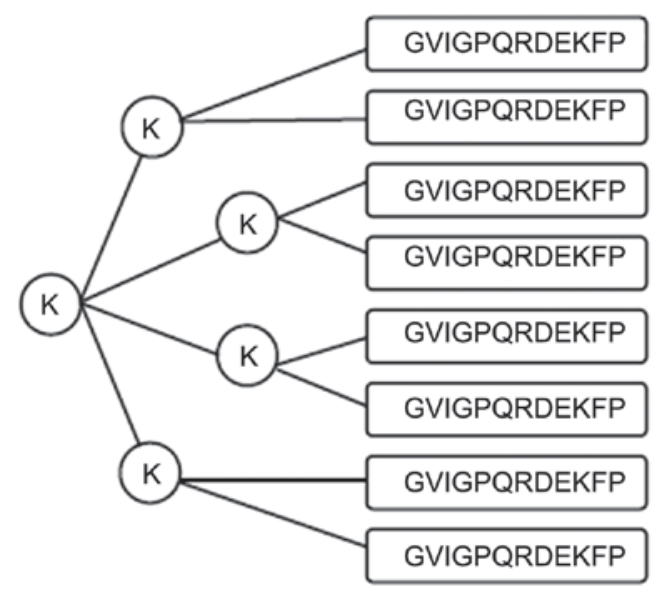

Figure 3. Schematic structure of eight-branched peptide multiple antigenic polypeptides. Amino acid peptides were linked with the 8 amino terminals of the 4 lysines located at the end of the MAP core structure. MAP, multiple antigenic polypeptide.

Therefore, two eight-branch MAPs (Fig. 3) were synthesized based on the predicted amino acid sequences (Table I).

Binding affinity of synthesized MAPs and $m T N F-\alpha$ full-length protein to anti-mTNF- $\alpha$ antibody. The binding affinity of synthesized MAP and mTNF- $\alpha$ full-length protein to anti-mTNF- $\alpha$ antibody was measured by indirect ELISA. On the basis of absorbance at a wavelength of $490 \mathrm{~nm}$, MAP1 and MAP2 exhibited rather high affinity to the commercialized antibody. The binding of MAP2 and mTNF- $\alpha$ full-length protein to the antibody was stronger than that of MAP1 (Fig. 4).

Dynamic changes in mouse antibody titer. Specific antibodies were detected 2 weeks after the first immunization. The MAP1 antibody titer reached a plateau after 4 weeks with the mean highest measured antibody titer of 1:50,000. The MAP2 antibody titer reached the mean highest antibody titer of 1:130,000 6 weeks after immunization and peaked at 8 weeks. The mean highest antibody titer for MAP2 was 1:140,000. No antibodies were generated in the MTNF- $\alpha$ and PBS control groups (Fig. 5). Furthermore, no reactions between TH and the two MAP antiserums, or cross-reactions between the two serums and two MAPs were observed.

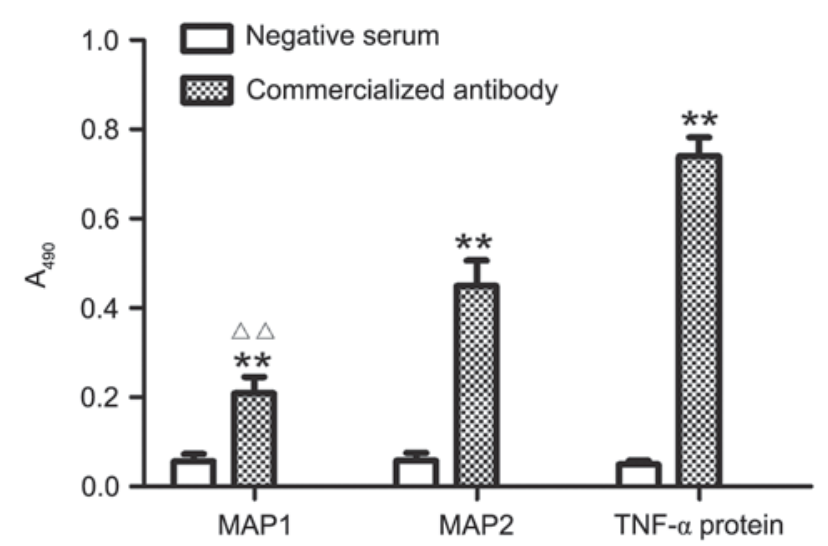

Figure 4. Binding affinity of MAP1 or MAP2 with the commercial anti-mTNF- $\alpha$ antibody (rabbit anti-mouse full-length TNF- $\alpha$ protein). MAP, multiple antigenic polypeptide; mTNF- $\alpha$, mouse tumor necrosis factor- $\alpha$; MAP1, amino acids 54-65 of mTNF- $\alpha$; MAP2, amino acids 78-92 of mTNF- $\alpha .{ }^{* *} \mathrm{P}<0.01$ vs. negative serum. ${ }^{\Delta \Delta} \mathrm{P}<0.01$ vs. MAP2 antiserum.

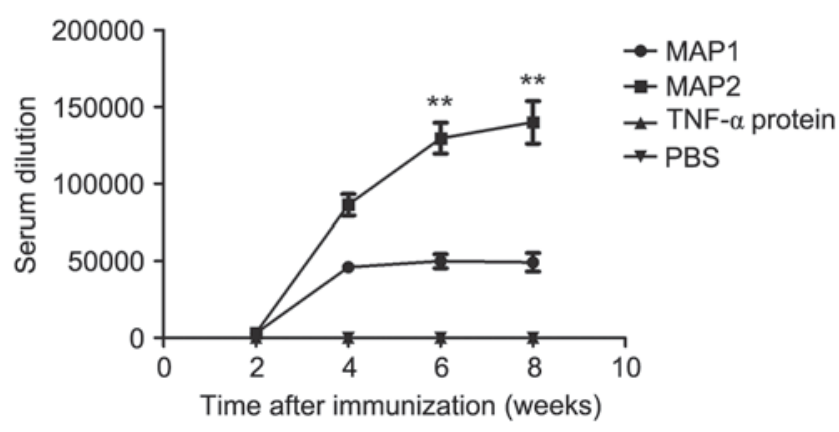

Figure 5. Dynamic changes of antibody titers in murine serum subsequent to immunization with different MAPs. MAP, multiple antigenic polypeptide; mTNF- $\alpha$, mouse tumor necrosis factor- $\alpha$; MAP1, amino acids 54-65 of mTNF- $\alpha$; MAP2, amino acids 78-92 of mTNF- $\alpha$; PBS, phosphate-buffered saline. ${ }^{* *} \mathrm{P}<0.01$ vs. MAP1 antibody titer.

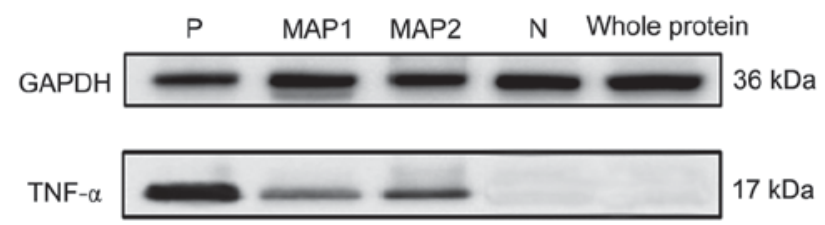

Figure 6. Specificity of the murine antisera against MAPs as detected by western blotting. P, positive control (commercialized TNF- $\alpha$ antibody); $\mathrm{N}$, negative control ( $\mathrm{TH}$ peptide antiserum); whole protein, recombinant TNF- $\alpha$ whole protein antiserum; MAP, multiple antigenic polypeptide; mTNF- $\alpha$, mouse tumor necrosis factor- $\alpha$; MAP1, amino acids 54-65 of mTNF- $\alpha$; MAP2, amino acids 78-92 of mTNF- $\alpha$.

Protein electrophoresis and western blotting. Total protein from H22 cells was used to evaluate the MAP1 antiserum, MAP2 antiserum and commercial mTNF- $\alpha$ antiserum. A commercial rabbit anti-mouse TNF- $\alpha$ antibody served as a positive control and a mouse pre-immune serum served as a negative control. Glyceraldehyde-3-phosphate dehydrogenase was selected as an internal reference. A very clear band was observed in a molecular weight of $\sim 17 \mathrm{kDa}$ from the commercial antibody. This was also observed for for MAP1 and MAP2 antiserums. Based upon a commercial antibody datasheet, $17 \mathrm{kDa}$ indicated 
the mTNF- $\alpha$ protein. The mTNF- $\alpha$ recombinant protein antiserum and negative controls did not exhibit a band (Fig. 6).

\section{Discussion}

The prevalence of UC has increased in China in recent years. Without effective treatment, its persistence and recurrent attacks severely affect the quality of life. TNF- $\alpha$ has emerged as a target for the treatment of UC $(11,12)$.

The bioactivity of TNF- $\alpha$, a human self-antigen, is complicated. Studies have demonstrated that TNF- $\alpha$ overexpression co-produces various types of disease, such as inflammatory bowel disease $(3,4,6,7)$. Anti-TNF- $\alpha$ monoclonal antibody (infliximab) is the most commonly used antibody for passive immunotherapy. It neutralizes TNF- $\alpha$ in vivo and alleviates pathological damage. Infliximab has been approved for the treatment of Crohn's disease, and its positive role in UC treatment has been confirmed by clinical studies $(11,12)$. However, anti-TNF- $\alpha$ monoclonal antibody treatment has various drawbacks. It is associated with high medication volume use and high production cost. This type of treatment also requires long-term repeated use and is prone to causing hypersensitivity reactions $(13,14)$. This has given a new direction for developing anti-self molecule immunotherapies, and active immunization vaccines against human self-proteins (autologous vaccines) rather than passive acceptance of monoclonal antibody drugs (15). Autoantigen epitope vaccines present as a better treatment modality for autoimmune disease. Due to their low molecular weight and unitary structure, self-antigens reduce immunogenicity and cannot induce the desired immune responses, particularly in B-cell epitope-mediated humoral immune responses (16). To solve this problem, short peptide vaccine epitope and carrier protein crosslinking methods were used to improve immunogenicity. However, carrier proteins are foreign antigen molecules and often induce antibodies against the carrier protein itself rather than the vaccine epitopes. In recent years, a design for MAPs has been proposed. Low-molecular weight and low-immunogenicity lysines are used as the core matrix coupling monomeric peptides (usually four or eight) to form a dendritic structure. Such a design mimics the natural conformational epitopes, but also activates humoral immunity and induces high-titer and high-affinity antibodies without coupling to a carrier protein (17). Therefore, the use of a branched MAP epitope complex designed using an MAP program may improve the quality of peptide vaccines with the removal of carrier protein defects.

The present study was based on previous investigations of a heparanase MAP vaccination strategy (18-22), with the establishment of a method to induce a high-titer humoral immune response (23). To achieve the inhibition of TNF- $\alpha$, internet software was used to predict the TNF- $\alpha$ B-cell epitope and an optimized immunization strategy (MAP $+\mathrm{T}$ cell epitope peptide) was used to induce high titers of antibody in vivo. To validate the immunogenic specificity of the predicted B-cell epitopes, the corresponding MAP, together with T-helper epitope for polyclonal antisera, was synthesized and the $\mathrm{BALB} / \mathrm{c}$ mice were immunized. ELISA results demonstrated that MAP1 and MAP2 induced TNF- $\alpha$-specific antibodies in vivo, with a higher-titer antibody observed in MAP2, which indicated a high affinity to the commercial full-length antibody. This suggested that MAP1 and MAP2 were possible epitope peptides, with MAP2 located in amino acids 78-92 and demonstrating a slightly higher immunogenicity. MAP2 is more likely an immunogen for inducing highly specific humoral immune response to TNF- $\alpha$.

To further verify the specificity of the antibody produced by MAP immunization, total protein was extracted from mouse hepatoma H22 cells, that were stably expressing mTNF- $\alpha$, and reacted with MAP1 antiserum, MAP2 antiserum, and commercial mTNF- $\alpha$ recombinant protein antiserum. A commercial rabbit anti-mouse mTNF- $\alpha$ antibody served as positive control, with the corresponding pre-immune mouse serum serving as a negative control. The results demonstrated a clear band at a molecular weight of $\sim 17 \mathrm{kDa}$ for MAP1 and MAP2, but no clear bands were observed for mTNF- $\alpha$ recombinant protein antiserum and the negative control. The western blotting results demonstrated that $\mathrm{mTNF}_{-} \alpha$, as a self-antigen, could not induce a specific humoral immune response alone, whereas the MAP strategy could markedly enhance its B-cell epitope immunogenicity and induce polyclonal antibodies specifically for TNF- $\alpha$.

In conclusion, the results of the present study indicated that amino acids 54-65 and 78-92 of mTNF- $\alpha$ were B-cell epitopes, with the strongest immunogenicity for amino acids 78-92. The study provided a theoretical basis for further investigations into a TNF- $\alpha$ polypeptide antibody and B-cell peptide vaccine. However, there were some limitations in this study, such as the optimal dose of MAP was not attentively selected, and the possibility of inducing autoimmune diseases or hypersensitivity reactions were not fully investigated. In addition, for TNF- $\alpha$ immunotherapy, further studies are required to clarify whether the above-mentioned B-cell epitopes are neutralizing epitopes of TNF- $\alpha$, which inhibit TNF- $\alpha$ activity after binding and facilitate with the treatment of inflammatory bowel disease.

\section{Acknowledgements}

The present study was supported by the National Natural Science Foundation of China (grant no. 81400682) and Zhejiang pharmaceutical and health care plans (grant no. 2013KYA014).

\section{References}

1. Park JH and Brentjens RJ: Adoptive immunotherapy for B-cell malignancies with autologous chimeric antigen receptor modified tumor targeted T cells. Discov Med 9: 277-288, 2010.

2. Castro FV, Al-Muftah M, Mulryan K, Jiang HR, Drijfhout JW, Ali S, Rutkowski AJ, Kalaitsidou M, Gilham DE and Stern PL: Regulation of autologous immunity to the mouse 5T4 oncofoetal antigen: Implications for immunotherapy. Cancer Immunol Immunother 61: 1005-1018, 2012.

3. Kopylov U, Ben-Horin S, Zmora O, Eliakim R and Katz LH: Anti-tumor necrosis factor and postoperative complications in Crohn's disease: Systematic review and meta-analysis. Inflamm Bowel Dis 18: 2404-2413, 2012.

4. Kawalec P, Mikrut A, Wiśniewska N and Pilc A: Tumor necrosis factor- $\alpha$ antibodies (infliximab, adalimumab and certolizumab) in Crohn's disease: Systematic review and meta-analysis. Arch Med Sci 9: 765-779, 2013.

5. Marchioni RM and Lichtenstein GR: Tumor necrosis factor- $\alpha$ inhibitor therapy and fetal risk: A systematic literature review. World J Gastroenterol 19: 2591-2602, 2013. 
6. Laharie D, Bourreille A, Branche J, Allez M, Bouhnik Y, Filippi J, Zerbib F, Savoye G, Nachury M, Moreau J, et al: Ciclosporin versus infliximab in patients with severe ulcerative colitis refractory to intravenous steroids: A parallel, open-label randomised controlled trial. Lancet 380: 1909-1915, 2012.

7. Reinisch W, Sandborn WJ, Rutgeerts P, Feagan BG, Rachmilewitz D, Hanauer SB, Lichtenstein GR, de Villiers WJ, Blank M, Lang Y, et al: Long-term infliximab maintenance therapy for ulcerative colitis: The ACT-1 and -2 extension studies. Inflamm Bowel Dis 18: 201-211, 2012.

8. Jun Y, Hong Z and Jie T: The study of mouse TNF- $\alpha$ functional domain and its neutralizing antibody binding site. Prog Biochem Biophys 36: 430, 2009.

9. Amexis G and Young NS: Multiple antigenic peptides as vaccine platform for the induction of humoral responses against dengue-2 virus. Viral Immunol 20: 657-663, 2007.

10. Dechamma HJ, Dighe V, Kumar CA, Singh RP, Jagadish M and Kumar S: Identification of T-helper and linear B epitope in the hypervariable region of nucleocapsid protein of PPRV and its use in the development of specific antibodies to detect viral antigen. Vet Microbiol 118: 201-211, 2006.

11. Thorlund K, Druyts E, Mills EJ, Fedorak RN and Marshall JK: Adalimumab versus infliximab for the treatment of moderate to severe ulcerative colitis in adult patients naïve to anti-TNF therapy: An indirect treatment comparison meta-analysis J Crohns Colitis 8: 571-581, 2014.

12. Fausel R and Afzali A: Biologics in the management of ulcerative colitis-comparative safety and efficacy of TNF- $\alpha$ antagonists. Ther Clin Risk Manag 11: 63-73, 2015.

13. Marehbian J, Arrighi HM, Hass S, Tian H and Sandborn WJ: Adverse events associated with common therapy regimens for moderate-to-severe Crohn's disease. Am J Gastroenterol 104: 2524-2533, 2009.

14. Can super-antibody drugs be tamed? Nature 440: $855-856$, 2006.

15. Rolinski J and Hus I: Breaking immunotolerance of tumors: A new perspective for dendritic cell therapy. J Immunotoxicol 11: 311-318, 2014.

16. Park KB, Lim BK, Ye MB, Chung SY and Nam JH: A peptide vaccine based on a B-cell epitope on the VP1 protein of enterovirus 70 induces a strong antibody response. Acta Virol 56: $337-342,2012$
17. Haro I and Gómara MJ: Design of synthetic peptidic constructs for the vaccine development against viral infections. Curr Protein Pept Sci 5: 425-433, 2004.

18. Zhang J, Yang JM, Wang HJ, Ru GQ and Fan DM: Synthesized multiple antigenic polypeptide vaccine based on B-cell epitopes of human heparanase could elicit a potent antimetastatic effect on human hepatocellular carcinoma in vivo. PLoS One 8: e52940, 2013.

19. Zhang J, Yang J, Fan D, Tao H, Wang H and Yu T: Peptide FLNPDVLDI of heparanase is a novel HLA-A2-restricted CTL epitope and elicits potent immunological antitumor effects in vitro with an 8-branched design. Oncol Rep 29: 1955-1961, 2013.

20. Zhang J, Fan DM and Yang JM: Immunotherapy targeting Heparanase-1 may be the the dawn of cancer sufferers. J Gastroen Hepatol Res 1: 3, 2012.

21. Zhang J, Yang J, Han X, Zhao Z, Du L, Yu T and Wang H: Overexpression of heparanase multiple antigenic peptide 2 is associated with poor prognosis in gastric cancer: Potential for therapy. Oncol Lett 4: 178-182, 2012.

22. Zhang J, Yang J, Cai Y, Jin N, Wang H and Yu T: Multiple antigenic polypeptide composed of heparanase B-cell epitopes shrinks human hepatocellular carcinoma in mice. Oncol Rep 33: 1248-1256, 2015

23. Du L, Wang H, Yang J, Gao H, Zhou Y and Tao H: T-helper epitope peptide improves immunological effects of the B cell epitopes of human heparanase protein. Chin J Microbiol Immunol: 869-872, 2008 . 